\title{
Türk Kültüründe İknanın Atasözleri Bağlamında İncelenmesi
}

\author{
Fatih CEYLAN* (D)
}

\begin{abstract}
ÖZ
İçinde yaşadığımız çağda demokrasi, insan hakları, özgürlükler, üretim ve bilgi iletişim teknolojilerinde yaşanan baş döndürücü gelişmelere bağlı olarak insanlar artk yaşam boyu hemen hemen her işini yapmada ve ihtiyaçlarını karşılamada çok fazla alternatifle karşılaşmakta ve tercih yapma durumunda kalmaktadır. Bundan dolayı ikna olgusunun insan hayatındaki yeri, önemi ve kullanıldığ1 alanlar gün geçtikçe artmaktadır. Bu bağlamda ele alınan çalışmanın amacı, Türk toplumunun ikna olgusuna verdiği önemi ve ikna ile ilgili vurgu yaptığı faktörleri ortaya koymaktır. İçerik analizi yöntemiyle yapilan bu çalışmadan elde edilen bulgular incelendiğinde; Türk toplumunun tutum değiştirme/oluşturma yöntemlerinden en çok "ikna etme" yöntemini benimsediği, ikna edecek kişide olması gereken özellikler ve iknayı kolaylaştıran faktörlerden en çok "etkili ve güzel konuşma" faktörüne önem verdiği ve iknayı zorlaștıran faktörlerden ise en çok "alıcının yapısal ve donanımsal eksiklikleri" faktörüne vurgu yaptı̆̆ sonuçlarına ulaşılmıstır. Çalışmanın sonunda bu sonuçlarla ilgili olarak gelecekte Türk toplumu üzerine ikna çalışması yapacak olan politikacılara, araşturmacılara, kısaca konuyla ilgilenen her kişiye veya kuruma bazı öneriler getirilmiştir.
\end{abstract}

Anahtar Kelimeler: Türk kültürü, Atasözleri, İkna.

\section{Investigation of Persuasion in Turkish Culture in the Proverbs}

\begin{abstract}
Due to the remarkable developments in democracy, human rights, freedoms, production, and information communication technologies in our age, people now have many alternatives in doing almost every job and meeting their own needs throughout their life. Therefore, the place of persuasion in human life, its importance, and usage areas are increasing day by day. The aim of the study in this context is to reveal the importance Turkish society attaches to the phenomenon of persuasion and the factors emphasized on persuasion. When the findings obtained from the content analysis were examined, Turkish society mostly adopted the method of "persuasion" among the methods of changing/creating an attitude. They gave great importance to the "effective and good speech" factor in terms of the characteristics of the person who convince and the factors that facilitate the persuasion. They accepted the "receiver's structural and knowledge deficiencies" as the factor that makes persuasion difficult. At the end of this study, some suggestions were provided to politicians, researchers, and anyone or any institution interested in the studies on persuasion in Turkish society in the future.
\end{abstract}

Keywords: Turkish culture, Proverbs, Persuasion.

\section{Giriş}

İnsan sosyal bir varlık olduğu için hayat boyu diğer insanlarla yoğun bir şekilde iletişim kurmaktadır. Çünkü insanın gündelik hayatta ihtiyaçlarını karşılamak için sürekli iletişim kurarak kendini diğer insanlara anlatması ve kendinin de diğer insanları anlaması gerekmektedir. Bu iletişimlerin çoğunluğunun amacı karş1 tarafı etkilemek, belli bir inanca, duyguya, düşünceye veya davranışa yönlendirmek (Akyol, 2019, s. 4), başka bir ifadeyle ikna etmektir. Bundan dolayı ikna eylemi, insanların birbirleriyle kurdukları her türlü iletişimde karşı tarafin tutum ve davranışlarını etkilemek ve yönlendirmek için başvurulan önemli bir faktördür (Tarakçı, 2019, s. 7).

"İkna çalışmalarının kökü Carl Hovland ve arkadaşlarının Yale İletişim Araştırmaları projesi kapsamında 1950'lerde propaganda teknikleri üzerine yürüttükleri çalışmalara dayanmaktadır" (Demirtaş, 2004, s. 75). Bu öncü çalışmalardan sonra ikna kavramı ve süreci ile ilgili çalışmaların artmaya başladığı, özellikle son yıllarda ikna konusunda oldukça yoğun ve ciddi çalışmalar yapıldığı görülmektedir (Yiğitbaşı, 2012; Okur; Süğümlü \& Gökçen, 2013; Kurudayıŏlu \& Yılmaz, 2014; İplikçi, 2015; Tuna, 2016; Başarır, 2017; Huseynli; Engizek \& Kurtuluş, 2018; Christophe \& Renvoise, 2019; Ceylan, 2020; Üstündağ \& Akengin, 2020; Bahçecioğlu, 2021). Bunun sebebi olarak iknanın insan hayatındaki yeri ve önemi ile toplumsal gelişmişlik düzeyi arasında olan doğru orantılı ilişki gösterilebilir. Örneğin; ilk toplumsal yapılarda sosyo-ekonomik gelişmişlik düzeyi oldukça düşüktü. Oligarşi ve monarşi gibi despot yönetim şekilleri ve ataerkil aile yapısı ağırlıklı olarak benimsenmişti. Bu şekilde olan ilk toplumlarda gelecekte iktidarı kimin ele alacağı önceden belli olduğundan seçim ve seçmeni ikna çalışmalarına ihtiyaç duyulmamıştır. Ataerkil aile yapısı hâkim olduğundan başta evlilik olmak üzere birçok konuda gençler

\footnotetext{
*Ö̈̆r. Gör. Dr., Erzincan Binali Yıldırım Üniversitesi, fatcey25@gmail.com
}

Makalenin Gönderim Tarihi: 30.12.2020; Makalenin Kabul Tarihi: 29.03.2021 
hakkında kararlar aile büyükleri tarafindan verildiği için gençlerin kendileriyle ilgili birçok konuda bireysel olarak ikna edilmesine gerek kalmamıştır. Benzer şekilde ilk toplumlarda çocukların büyüklere, kadınların da erkeklere itiraz etme hakları olmadığından, onların da birçok konuda ikna edilmeleri söz konusu olmamıstır. Şüphesiz ki insanlığın ilk yaşam formlarıyla ilgili bu şekildeki örnekleri çoğaltmak mümkündür. $\mathrm{Bu}$ örnekler, ilk toplumsal yapılarda insanların yaşamlarında tercih etme ve ikna etme/edilme olgularıyla günümüzdeki kadar yoğun bir şekilde karşı karşıya kalmadıklarını göstermektedir. Buna karşın toplumsal gelişmişlik düzeyi arttıkça bireylerin ekonomik olarak özgürleştiği, despot yönetimlerin azaldığ1demokrasilerin yaygınlaştı̆̆ birlikte insan hayatındaki her unsurla ilgili alternatiflerin oldukça arttığı görülmektedir. Tarihsel süreçte sosyo-ekonomik-politik ve teknolojik yönlerden devaml gelişerek günümüzdeki formuna ulaşan çağdaş toplumlarda insan hayatını ilgilendiren her konuda ve her işte alternatiflerin gittikçe artması, insanların tercih ve ikna olgularıyla çok yoğun bir şekilde karşılaşmalarına sebep olmuştur. Özellikle sıcak savaşların yerini soğuk savaşların aldığı ve hemen her işte başarıllı olmak için algının çok önemli bir faktör olduğu günümüzde ikna olgusunun önemi daha da artmıştır. Bundan dolayı günümüzde insanları anlamak ve yönlendirmek için onların ikna edilmesi, başka bir ifadeyle razı edilmesi son derece elzem bir konu haline gelmiştir. İnsanlant ikna edebilmek için de onların eğilimlerini ve önem verdikleri faktörleri bilmek gerekir. Bu kapsamda ele alınan bu çalısmada kültürün en önemli göstergelerinden biri olan atasözleri bağlamında Türk kültüründe "ikna etme/rıza alma" yöntemine ne kadar vurgu yapıldığı, ikna etmeyi kolaylaştıran ve zorlaştıran faktörlerden hangisi ya da hangilerinin vurgulandığı ve ikna edecek kişide olması gereken özellikler olarak nelerin ön plana çıkarıldığı ortaya konulmaya çalışılmıştır.

\section{Kuramsal Çerçeve}

\subsection{Tutumlar ve İkna}

Bireyin duygu ve düşüncelerinin belirli bir yönde ve eğilimde olması anlamına gelen tutum, insan davranışlarının kaynağını oluşturmaktadır. Tutumlar genellikle bireyin içinde yaşadığı sosyal çevre tarafindan şekillenir (Usal \& Kuşluvan, 1999, s. 128). Başka bir ifadeyle sosyal bir varlık olduğu için insanın tutum, düşünce ve davranışları, hayatı boyunca başta içinde yaşadığı sosyal çevredeki insanlar olmak üzere, diğer insanlarla kurduğu iletişimlerin bir sonucu olarak şekillenmektedir. Dolayısıyla insanlar tüm yaşamı boyunca değişik sebeplerle birbirleriyle iletişim kurarlar ve kurulan iletişimlerin birçoğunda birbirlerinin tutum ve davranışlarının şekillenmesini sağlarlar.

Toplumbilimciler bireylerin tutum, inanç, düşünce ve davranışlarını değiştirmede ve halka bir şey yaptırmada etkili olan üç temel yöntem olduğunu belirtmektedirler. Bunlar; ikna etmek, maddi çıar/para sağlamak ve zor kullanmaktır (Asna, 1968, s. 59; Tortop, 1986, s. 5; Anık, 1997, s. 105; Balc1, 2006, s. 6; İplikçi, 2015, s. 67). Şüphesiz ki bu yöntemlerden ikna etme, başka bir ifadeyle razı ederek istenilen yöne çekme, en geçerli ve en ekonomik bir yöntemdir (Küçükkurt, 1987, s. 43). İkna etme veya rıza alma, aynı zamanda ilgili konuda karşı tarafta oluşturulan tutumun sürdürülebilirliği açısından da en etkili yoldur. Örneğin; siyasal alanda Montesquieu'nun Kanunlarn Rubu Üzerine (2004) ve Rousseau'nun Toplum Sözleşmesi (2012) isimli eserlerinde ve Gramsci'nin hegemonya kavramı bağlamında zora dayalı hiçbir gücün uzun süre ayakta kalamayacağı vurgulanmaktadır. Siyasal iktidar açısından tespit edilen bu durumun diğer alanlar için de geçerli olduğu genel kabul gören bir olgudur, çünkü çağdaş modern toplumlarda artik zor gücüyle oluşturulan hiçbir durum, olay veya olgu sürdürülebilir olmaktan uzaktır. Bu noktada maddi kazanç veya para sağlama yöntemiyle oluşturulan bir tutumun da sürdürülebilir olmadığını belirtmek gerekir. Daha fazla maddi kazanç sağlanması durumunda insanlar daha önce benimsedikleri tutum veya davranışlarını değiştirebilirler. Sonuç olarak insanların inanç, tutum ve davranışlarını etkileme, değiştirme veya sağlamlaştırma noktasında "ikna etme veya rıza alma" yönteminin en etkili ve sürdürülebilir bir yöntem olduğu anlaşılmaktadır.

Özü Arapça olan ve Türkçe’ye kandırma, inandırma olarak geçen ikna kavramının (Anık, 200, s. 31), literatürde bilimsel olarak ilk kez "retorik" (söz söyleme sanatı) olgusuyla birlikte ele alındığ1 görülmektedir. M. Ö. V. yüzyllda Sicilya'da tiranların egemenliğine son veren halk, mülklerini geri almak için kurulan mahkemelerde kendi davalarını savunma durumunda kalmış ve bu savunmalarda hakkını etkili ve güzel bir şekilde konuşarak savunanların mülklerini geri aldığı görülürken, savunamayanların alamadığı 
görülmüştür. $\mathrm{Bu}$ durumda etkili konuşma yeteneğinin, başka bir ifadeyle ikna edici konuşmanın ögrenilebilir/öğretilebilir bir olgu olduğu anlaşılmıştır (Reboul, 1996'dan Aktaran Altınörs, 2011, s. 83). Bu şekilde ortaya çıkan retorik olgusuyla birlikte "ikna" kavramının da artık bilimsel olarak ele alınmaya başlandığı görülmektedir. Ancak her ne kadar da Antik Yunan'da önce Sofist Gorgias, Sokrates ve Platon gibi düşünürler tarafından ele alınmış olsa da retorik kavramını bilimsel olarak ele alan ilk düşünür Aristoteles olmuştur. Diğer bir deyişle Aristoteles tarafindan ele alınan retorik kavramı/olgusu, bilimsel anlamda ikna ile ilgili ilk ve önemli bir çalışma olarak kabul edilmektedir (Demirtaş, 2004, s. 74).

Antik çăglardan beri ortaya çıkan teknolojik gelişmeler insanoğlunun yaşam şeklini önemli derecede değiştirmiştir. İlk yaşam formlarında kırsalda ve bireysel bir şekilde hayat süren insanoğlu birbirine daha az ihtiyaç duymakta ve birbirleriyle daha az iletişim kurmaktaydı. Buna karşın her alanda yaşanan teknolojik gelişmeler sonucu giderek daha da gelişen ve kalabalıklaşan şehirlerde yaşayan insanoğlu bir arada, birbirine daha bağlı ve birbirleriyle daha çok iletişime dayalı bir hayat şekli sürmeye başlamıştır. Modern toplumlar olarak da adlandırılan bu yeni toplumlar gün geçtikçe daha da gelişmekte ve buna bağlı olarak insanlar giderek birbirlerine daha çok bağlı hale gelmektedir. Bu durumun kaçınılmaz bir sonucu olarak insanlar birbirlerinin tutum ve davranışlarını daha çok etkilemekte ve birbirlerini ikna etme durumuyla daha sık karşı karşıya kalmaktadır. Başka bir ifadeyle sanayi, üretim, teknolojide ve kitle iletişim araçlarındaki hızlı gelişmelerle birlikte ortaya çıkan modern çağda ikna olgusunun kullanım alanlanı, araçları ve amaçları oldukça genişlemiş ve birçok alanda yoğun olarak kullanılan bir olgu durumuna gelmiştir. Yaşanan bu gelişmelere bağlı olarak sürekli gelişen, değişen ve farklı alanlara yayılan ikna kavramıyla ilgili literatürde farklı yazarlar tarafindan birbirini tamamlayan ve birbirine yakın tanımlar (Balcı, 2006, s. 7) yapıldığ1 görülmüştür.

Aristoteles'e (2015, s. 35) göre ikna, "belli bir durumda, elde var olan inandırma yollarını kullanma yetisidir". Brembeck ve Howell ikna kavramını önceki çalışmalarında (1952, s. 24), "önceden belirlenmiş sonuçlara ulaşmak amacıyla, bilinçli olarak, insan güdülerinin manipülasyonu yoluyla düşünce ve eylemlerinin değiştirtilmesi girişimi”" olarak tanımlamışlar ve daha sonraki çalışmalarında (1976, s. 9) ise bu tanımı "bireylerin seçimlerini etkileme amaçlı iletişimi" şeklinde kısaltmışlardır. Kapferer'e göre ikna "davranışların, niyetlerin, duyguların, kanaatlerin değiş̧tirilmesi ya da değiştirilmemesine yönelik olarak ileti enformasyonundan yararlanılan psikolojik süreçtir" (Kapferer, 1978'den Aktaran Anık, 1997, s. 107). Raven ve Haley (1982, p. 427) iknayı, "bir bireyin etkisiyle birey ya da bireylerin biliş, tutum ya da davranışlarında değişiklik yaratılmasıdır" şeklinde tanımlarken; Bettinghaus ve Cody (1987, p. 3) ise iknaının tanımının "bireyin gönderdiği mesajlarla diğer birey ya da grupların hareket, fikir ve inançlarını bilinçli olarak değiştirme çabası" olduğunu belirtmiştir. Bir başka tanıma göre ikna, "ikna edilen kişinin/hedef kitlenin bir miktar özgürlüğe sahip olduğu bir durumda iletişim yoluyla bir başkasının zihnini etkileme amaçlı başarılı bir kasıtlı çabadır" (O’Keefe, 1990, p. 17), iken bir diğerine göre ise "ikna çabası içinde olan bireyin, çeşitli duygusal ve bilişsel teknikler yoluyla bir başka bireyin belirli bir davranış, inanç ya da tutumu benimsemesine rehberlik etmektir" (Reardon, 1991, p. 2). Yüksel (2005, s. 4) göre ise ikna "kanaat ettirme, kanaat verebilme; kandırma, razı etme, inandırmadır". İkna kavramılla yapılan farklı tanımlara bakıldığında, yukarıda da bahsedildiği gibi bu tanımların birbirlerine yakın ve birbirlerinin eksik yönlerini tamamlayan nitelikte oldukları görülmektedir.

İkna ile ilgili yapılan farklı tanımlardan hareketle Perloff (2010, p. 12-16) iknayı, özgürce seçim yapılan bir ortamda, alıciya iletilen bir ileti/mesaj yoluyla birey ya da bireylerin bir konu hakkinda sahip olduklar1 davranış ve tutumların değiştirilmesinin amaçlandığı sembolik bir süreç, şeklinde tanımlayarak, iknanın sahip olduğu beş unsur olduğunu belirmiştir. Bu unsurlar şunlardır:

Öncelikle ikna, belirli sayıda adımdan oluşan bir süreçtir ve alıcının aktif bir şekilde bu sürece katılımını gerektirir. İkinci olarak iknada başka bir kişiyi, alıcıyı veya hedefi etkilemek amacıyla bilinçli bir girişim vardır. Üçüncü olarak iknada iletişimci alıcıyı iknaya zorlayamaz. İletişimci gerekli argümanı sağlar, alıcının arzularını harekete geçirir, düşüncelerinin altındaki mantuğı ona gösterir. Sonra alıcı değişimi ya gerçekleştirir ya da reddeder. Bazen alıcı konumundaki birey ya da bireyler kendi kendilerini ikna edebilirler. Dördüncü olarak ikna iletişimsel bir eylem olduğundan, ikna etmek için diğer toplumsal etkileme şekillerinin aksine olgusal veya duygusal, mantıklı veya mantıksız, sözlü veya sözsüz, kişiler arası veya kitle iletişim araçları aracılı̆̆yla aktarılabilen bir mesaj olmalıdır. Son olarak ikna, özgür bir seçim 
ortamı ve imkânı gerektirir. Bu unsurlardan da anlaşıldığı gibi ikna olgusu bir dayatma veya zorlama eylemi değil (Elden \& Bakır, 2010, s. 25), aksine bireylerin tutum ve davranışlarını birtakım kanıtlama ve akıl yürütmelerle gönüllü olarak etkileme ve değiştirme eylemidir (Bilgin, 2003, s. 163; Tutar, 2014, s. 183).

İkna, her zaman hedefteki kişi ya da kişilerin var olan tutum ve davranışlannı değiştirme işi değil, aynı zamanda bazı konularda mevcut olan düşüncelerini korumaları ve değişikliğe karşı koymalarını sağlama işidir (Jamieson, 1996, p. 4-5). Dolayısıyla ikna olgusunda niyet önemlidir. Örneğin, reklamcılıkta bir mal veya hizmeti satın almayan müşterilere yönelik yapılan ikna çalışmalarında amaç hedef kitlenin tutum ve davranışlarını değiştirmek iken; diğer taraftan satın alınan ürün ya da hizmetin devamlılığı için yapılan ikna çalışmalarında ise amaç hedef kitlenin tutum ve davranışlarının korunmasını, sağlamlaştırılmasını ve sürdürülmesini sağlamaktır (Güz, 1998, s. 192). Yine bir siyasi parti, siyasal reklam çalş̧malarında bir taraftan kendine oy veren eski seçmenlerinin mevcut tutumlarını korumaya yönelik ikna çalışması yaparken; diğer taraftan yeni seçmenlerin veya başka partilere oy veren seçmenlerin tutumlarını değiştirmeye yönelik ikna çalışması yapmaktadır (Yiğitbaşı, 2012, s. 7). Dolayısıyla ikna tek yönlü ve basit bir eylem değil, aksine çok yönlü ve çok fazla faktörün etkili olduğu karmaşı bir eylemdir.

Sonuç itibariyle ikna, bir eylemi anlatan bir kavram olmasına rağmen, bu eylemin gerçekleşme sürecinde çok fazla faktörün etkili olduğu durumu göz önüne alındığında, anlaşılması ve gerçekleştirilmesi zor bir eylemdir. Öncelikle ikna iletişimsel bir eylem olduğu için iletişim sürecinde yer alan kaynak, kodlama, mesaj, kanal, gürültü, alıc1, kod açma ve geri bildirim gibi tüm faktörler ikna sürecinde de önemli derecede etkilidir. Yine bu faktörlerin her birini etkileyen alt faktörler de iknayı etkilemektedir. Ayrıca iknada hedef insan olduğu için insanı etkileyen ve şekillendiren kültür, coğrafya, din, gelenek-görenek gibi dış faktörler ve psikolojik yapı gibi iç faktörler de ikna sürecinde oldukça etkilidir. Tüm bunlar düşünüldüğünde ikna olgusunun karmaşıklı̆ı ve zorluğu daha iyi anlaşılmaktadır. Bundan dolayı ikna kavramıyla ilgili yapılan hiçbir çalşsmanın konuyu yüzde yüz ve tam bir şekilde ortaya koyması mümkün değildir.

\subsection{Kültür, Atasözleri ve Zihinsel Yapının İnşası}

Kültür, farklı düşünürler tarafindan çok sayıda tanımı yapılmış bir kavram olmasına rağmen, üzerinde herkes tarafından görüş birliği sağlanmış tek bir tanımı olmayan, içinde birçok parametreyi barındıran karmaşık bir kavramdır. Kavramla ilgili en kapsamlı tanımı yapan düşünürlerden biri olan Tylor’a (1985, p. 3) göre kültür, "insanın öğrendiği, benimsediği, bilgi, gelenek, görenek, sanat, ahlak ve benzeri alışkanlıklanı ve becerileri içine alan komplike bir bütündür". Başka bir tanıma göre kültür, "bir insan topluluğunu diğerinden ayıran ve her insan topluluğuna mahsus zihinsel oluşumlardır" (Hofstede, 1980, p. 29). Ziya Gökalp (1997, s. 25) ise kültürü, "sadece bir milletin dil, din, ahlak, sanat, felsefe, ak1l, hukuk ve iktisat ile ilgili yaşayışlarının ahenkli bir toplamıdır" şeklinde tanımlamaktadır. Tanımlannndan da anlaşıldığı gibi kültür, temel olarak iki farklı kategoriye ayrılmaktadır. Bunlardan biri maddi kültür, diğeri ise manevi kültürdür. Maddi kültür insanın ürettiği tüm maddi nesneleri kapsarken, manevi kültür ise din, gelenek, görenek, tutumlar, davranışlar, inançlar gibi toplumu şekillendiren tüm manevi ürünleri kapsamaktadır (Köknel, 1981, s. 18). Dolayssylla "kültür genel olarak bir toplumun 'maddi' ve 'manevi' değerler bütünü olarak tanımlanır" (Aktan \& Tutar, 2007, s. 2).

Bir toplumun geçmişten bugüne kadar her alanda oluşturduğu değerlerin tümünü kapsayan kültür, ait olduğu toplumun bireylerini bu değerlerle kuşatır (Topçu, 2011, s. 164). Onun için bir toplumu veya o toplumdaki bireyleri anlamak için o toplumun kültürünü anlamak gerekir. Kültürü anlamak için de kültürün alt boyutlarına bakmak gerekir. Şüphesiz ki kültürün en önemli boyutlarından biri de atasözleridir.

İlk insanlarla birlikte var olan ve anonim halk edebiyatının en önemli parçalarından biri olan atasözleri, eskiden beri sav, mesel (darb-1 mesel), makal, hikmet, tapma, tabir, samah, oranlama, kelam-1 kibar, ulular sözü ve atalar sözü gibi değişik isimlerle, sözlü gelenek ile nesilden nesile aktarllarak günümüze kadar gelmiştir. Her toplumda ve dilde var olan atasözleri, atalarımızın yaşamları boyunca uzun gözlem ve tecrübeleri sonucu oluşan, özelde içinden çıttğı toplum, genelde ise tüm insanllk için gerçeklik payı yüksek olan belirli kuralların, olguların ve durumların hikmetli sözler ya da öğütler biçiminde kalıplaştı̆ı sözlerdir (Pala, 1999, s. 5). Büyük çoğunluğu menşei itibariyle anonim olan atasözleri, pek az istisnalar dışında ilk defa kimin tarafindan ve ne zaman söylendiği bilinmeyen sözlerdir (Milli Kütüphane Başkanllğı, 1971, s. VII). 
Bir sözün atasözü olabilmesi için öncelikle ait olduğu ulusun her sınıfından bireyleri arasında binlerce kez tekrarlanmış olması ve bu şekilde tüm milletin vicdan ve tecrübe süzgecinden geçerek ayarı tam bir altına benzer şekilde değer ve revaç görmesi gerekir (Dilçin, 2000, s. XV). Böyle bir süreçten ve süzgeçten geçerek oluşan atasözlerinin belirli biçimsel ve kavramsal özellikleri vardır ve bunlar şu şekildedir: Atasözleri, çoğunluğu bir veya iki cümleden ibaret olan; doğa, sosyal ve toplumsal olgu ve olayların öteden beri nasıl olageldiklerini belirten; mantığa dayanarak insanlara doğrudan ahlak dersi ve nasihatler veren; birtakım bilgece fikirler, felsefeler ve gerçekler sunarak insanlara yol gösteren; bireylere bazı inanışları, töre ve geleneklerini bildirip-öğreten; az sözle çok şey anlatan; değiştirilemeyen ve yerlerine muadilleri konulamayan kısa, özlü, klişeleşmiş ve kalıplaşmış sözlerdir (Aksoy, 2015, s. 15-19).

Her toplumun kendi toplumsal yapısına uygun kanunu, kuralı, geleneği, göreneği olduğu gibi yine kendine özgü atasözleri vardır. Bir toplumun en önemli sözlü kültürel ürünlerden biri olan atasözleri, içinden çıktıkları toplumun kültürel mirasının en özlü ifadelerini oluşturur (Yaşar Uğurlu \& Harbi, 2018, s. 129). Bu bağlamda atasözleri, bir toplumun yaşayış biçimini ve dünya görüşünü yansıttı̆̆1 gibi kültürel tarihiyle ilgili de önemli ipuçları verir (Aksan, 2007, s. 38). Bundan dolay1 herhangi bir toplumun kültürel ve içtimai yapısının ne gibi aşamalardan geçtiği ne gibi değişimlere uğradığ1 ve bugün ne durumda olduğu konusunda bir şey öğrenilmek istenildiği zaman, o toplumun milli tarihi ve diğer özel ürünlerinin yanı sıra atasözlerini de muhtelif kategorilere ayırarak incelemek gerekir (Dilçin, 2000, s. XV). Çünkü "bir dilin söz varlığ1 içinde o toplumun bilgeliğini, dünya görüşünü ve anlatım gücünü ortaya koyan” (Yaşar, 2007, s. 146) atasözleri, her toplumun kendi öz benliğine ait özellikleri yansitır. Sözün özü, bir toplumun kuruluşundan bugüne kadar sergilediği yaşam şekilleri, gelenekleri, görenekleri, tutumları, davranışları, inanışları, düşünceleri, kısaca maddi ve manevi her şeyini nesilden nesile aktaran atasözleri, bu şekilde o toplumun kültürünün oluşmasını, sağlamlaşmasını, devam etmesini ve geleceğe taşınmasını sağlayan en önemli mihenk taşlanından biridir. Dahası atasözleri, ezelden beri bir toplumun değerlerini ve bireylerinin toplumsal hayatta sergilemesi beklenen kural ya da davranışları nesilden nesile devamlı olarak aktarmak suretiyle, o toplumun zihinsel yapısının inşasını ve gelecekte bu zihinsel yapının devam etmesini sağlayan en önemli kültürel faktörlerden biridir.

\section{Metodoloji}

\subsection{Araştırmanın Amacı ve Araştırma Soruları}

Bu çalışmanın temel amacı Türk kültüründe iknaya ne kadar önem verildiği ve hangi faktörler bağlamında ele alındığına dair 1şık tutmaktır. Başka bir ifadeyle bu araştırmada Türk toplumunun ikna olgusuna verdiği önem ve ikna ile ilgili vurguladı̆̆1 faktörlerin ortaya konulması amaçlanmıştır. Bu temel amacı gerçekleştirmek için çalışmada kültürün en önemli göstergelerinden biri olan atasözleri bağlamında "ikna" olgusunun incelenmesi amaçlanmaktadır.

Bu çalışmanın temel araştırma sorusu, Türk atasözleri bağlamında, Türk kültüründe "ikna” olgusu nasıl ele alınmaktadır? Bu temel sorunun cevabının bulunması için cevap aranan alt araştırma soruları şu şekildedir:

1. Türk atasözlerinde tutum değiştirme/oluşturma yöntemlerinden "İkna Etme”ye ne kadar vurgu yapilmıştur?

2. Türk atasözlerinde ikna etmeyi kolaylaştırmaya yönelik vurgu yapılan faktörler nelerdir?

3. Türk atasözlerinde ikna etmeyi zorlaştırmaya yönelik vurgu yapılan faktörler nelerdir?

4. Türk atasözlerinde ikna edecek kişide olması gereken özelliklere yönelik vurgu yapılan faktörler nelerdir?

\subsection{Araştırmanın Özgünlüğü ve Önemi}

Bu çalışma kapsamında yerli ve yabancı literatür taranmış, özellikle Türkçe literatürde ikna kavramını Türk Atasözleri bağlamında ele alan bir çalışmaya rastlanmamıştır. Türk kültüründe "ikna" olgusunun Atasözleri bağlamında ilk defa incelenmiş olması, bu çalışmayı özgün kılmaktadır. Elde edilen sonuç ya da sonuçlar ile Türk toplumunun ikna edilmesine yönelik araştırmacılara, politikacılara veya diğer alanlardaki tüm ilgililere 1şık tutması açısından ise bu çalışma önemli bir çalışmadır. 


\subsection{Araştırmanın Yöntemi}

Bu çalışmada nitel içerik analizi yöntemi kullanılmıştır. İletişim araştırmalarında ilk olarak Max Weber tarafından 1910 yılında, gazetelerin siyasi ve toplumsal olaylara verdikleri ağırlı̆̆ ortaya koymak amacıyla kullanılan bu yöntem (Geray, 2017, s. 146), Laswell ve Barelson gibi araştırmacıların öncül çalışmalarıyla gelişerek sosyal bilimlerde kullanılan en önemli araştırma yöntemlerinden biri haline gelmiştir (Timisi \& Dursun, 2003). Bir konu ile ilgili var olan verileri tanımlamaya ve verilerde gizli olabilen gerçekleri ortaya koymaya yönelik bir yöntem olan içerik analizinde (Herkner, 2003, p. 133), ele alınan konuya göre farklı teknikler kullanılmaktadır. Bu çalışmada bu tekniklerden biri olan "kategorisel analiz" kullanılmıştır. "Kategorisel analiz, genel olarak belirli bir mesajın önce birimlere bölünmesini ve ardından bu birimlerin, belirli kriterlere göre kategoriler halinde gruplandırılmasını ifade etmektedir” (Bilgin, 1999, s. 128). Dolayısıyla kategorisel analiz, incelenen birim sayısının çok olduğu ve birden çok kategorinin ve bu kategorilerin alt kategorilerinin olduğu araştırmalarda kullanılan en uygun yöntemdir (Balc1, 2006, s. 248).

Bu çalışmada önce Türk Atasözleri "doküman incelemesi” yöntemiyle taranmış ve "ikna” kavramıla ilgili olan atasözleri derlenmiştir. Daha sonra derlenen veriler incelenmiş ve anlam boyutuna göre benzer olanlar birleştirilerek kategoriler ve alt kategoriler oluşturulmuştur. Bu şekilde elde edilen bulgular "kategorisel analiz" yöntemiyle analiz edilmiş ve elde edilen sonuçlar tartış1lmıştır.

\subsection{Araştırmanın Evreni ve Örneklemi}

Bu araştırmanın evreni Türk kültürü, örneklemi Türk atasözleri ve ulaşılabilir örneklemi ise yazılı kaynaklardan erişilebilen Türk Atasözleridir. Bu araştırmada kullanılan örneklemin konuyu mümkün olduğu kadar iyi yansıtması için "doküman incelemesi” yöntemiyle derin odaklı veri toplaması yapılmıştır. Bunun için Türk atasözleri beş farklı kaynaktan taranmıştır. Yapılan taramalarda "tutum değiştirme/oluşturma yöntemleri” ve "ikna kavramı" ile ilgili olan atasözleri derlenmiştir. Tarama yapılan kaynaklar ve atasözleri sayılarının bilgileri aşağıda, Tablo 1'de verilmiştir.

Tablo 1. Veri Toplamada Taranan Kaynaklar

\begin{tabular}{cllc}
\hline No & \multicolumn{1}{c}{ Yazar Adı } & \multicolumn{1}{c}{ Eser Adı (Yılı) } & $\begin{array}{c}\text { Atasözü } \\
\text { Sayısı }\end{array}$ \\
\hline $\mathbf{1}$ & Milli Kütüphane Başkanlığ1 (MEB) & Türk Atasözleri I (1971) & 10730 \\
$\mathbf{2}$ & Ömer Asım AKSOY & Atasözleri ve Deyimler Sözlü̆̈̈ I-Atasözleri Sözlüğ̈̈ (2015) & 2667 \\
$\mathbf{3}$ & İskender PALA & Ata Sözleri (1999) & 1000 \\
$\mathbf{4}$ & Delhi DİLÇIN & Edebiyatımızda Atasözleri (2000) & 1620 \\
$\mathbf{5}$ & Özkul ÇOBANOĞLU & Türk Dünyası Ortak Atasözleri Sözlüğü (2004) & 1000 \\
\hline & & TOPLAM & $\mathbf{1 7 0 1 7}$ \\
\hline
\end{tabular}

Tablo 1'de görüldüğü gibi veri taraması beş farklı kaynaktan yapılmış ve toplam 17017 atasözü incelenmiştir. Tarama yapılan kaynakların içerdikleri atasözlerinin sayılarına bakıldığında, en kapsamlı sözlük Milli Kütüphane Başkanlığı tarafindan hazırlanan sözlük olup bunu sırasıyla Ömer Asım Aksoy’un, Delhi Dilçin'in, İskender Pala ve Özkul Çobanoğlu'nun hazırladıkları sözlükler takip etmektedir.

\subsection{Araştırmanın Sınırlılıkları}

$\mathrm{Bu}$ araştırmanın en önemli sınıll1lı̆ı, sözlü kültürün ürünü olan atasözlerinin bazılarının hep sözlü gelenekte kalması, bazılarının unutulması, bazılarının yerel sınırlar içerisinde kalması ve bazılannın ise müstehcenlik ve kötümserlik içermesi gibi değişik nedenlerle yazılı kaynaklara alınmamış olması gibi farklı nedenlerden dolayı hepsine ulaşılmasının mümkün olmamasıdır. Bu tip engellerden dolayı Türk atasözlerinin hepsine ulaşılamamıştır. Örneğin, içerdiği 10730 Atasözü ile konuyla ilgili en kapsamlı kaynak olan Milli Kütüphane Başkanlığının sözlüğüne bile müstehcenlik ve kötümserlik içeren, insanı hayata ve devlete küstüren, kadını hor ve hakir gören, Türkü ve Türk milletini küçük düşürücü, bireyi hırsızlı̆ga ve ahlaksızlığa teşvik edici nitelikte olan atasözleri alınmamıştır (1971, s. XIV). Bu durum bu araştırmanın en temel sinırlılı̆̆ıdır. Diğer bir sınırlılık ise bu konuda daha önce hazırlanmış standart bir formun (kategorileştirme ya da kodlama cetveli gibi) olmamasıdır. Araştırmacı tarafindan bu çalışmaya özgü olarak tasarlanan bu araştırma formu, konunun belirli bir çerçevede ele alınmasını sağlamaktadır. Aynı konu farklı araştırmacılar tarafindan farklı formlarla ve kapsamlarda ele alınabilir. 


\subsection{Kategorileştirme}

Nitel desenlerde, özellikle içerik analizi yönteminde kullanılan yöntemlerden biri olan kategorileştirmenin temel amacı bir çalışmada ele alınan değişkenlerin konuya uygun şekilde sınıflandırılmasını sağlamaktır. Türk kültüründe "ikna" kavramının atasözleri bağlamında incelenmesi konusunda daha önce yapılmış bir çalışmaya rastlanmamıştır. Bundan dolayı bu çalısmanın kategorileri araşurmacı tarafindan şu şekilde oluşturulmuştur:

Önce ilgili literatür taranmış ve farklı konularda da olsa benzer olan çalışmalar incelenmiştir. İncelemeler sonucunda bu çalışmanın temel kategorileri; "Tutum ve Davranışları Değiştirme/Oluşturma Yöntemleri”, “İkna Etmeyi Kolaylaştıran Faktörler", "İkna Etmeyi Zorlaştıran Faktörler" ve "İkna edecek Kişide Olması Gereken Özellikler", şeklinde dört başlıkta oluşturulmuştur. Daha sonra bu dört kategori bağlamında veri taraması yapılmıs ve bu kategorilerle ilgili olduğu tespit edilen veriler, ilgili kategorinin altında toplanmıştır. Sonra bu temel kategorilerin altında toplanan veriler (atasözleri) incelenmiş ve ilgili literatür de göz önüne alınarak anlam boyutuna göre alt kategoriler oluşturulmuştur. Son olarak bu şekilde oluşturulan araştırmanın kategorilerinin konuyu uygun bir şekilde yansıtıp yansıtmadığının anlaşılması için biri doçent ve ikisi profesörden oluşan toplam üç alan uzmanından, uzman görüşü alınmış ve gerekli görülen düzeltmeler yapılmıştır. Bu şekilde son şekli verilen araştırmanın kategorileri aşağıda, Tablo 2'de verilmiştir.

Tablo 2. Arasttrmann Kategorileri

\section{Kategori: TUTUM VE DAVRANIŞLARI DEĞİŞTİRME/OLUŞTURMA YÖNTEMLERİ}

\section{Alt Kategoriler}

1.1. İkna Etme/Riza Alma

1.2. Maddi Ç1kar/Para Sağlama

1.3. Zor Kullanma

\begin{tabular}{ll}
\hline & \\
\hline & Alt Kategoriler \\
2.1. & $\begin{array}{l}\text { Etkili ve Güzel } \\
\text { Konuşma }\end{array}$
\end{tabular}

2.2. Alıcinın Donanımlı Olmasi

2.3. Doğru Zamanlama

\subsection{Doğru Yöntem ve Araç Kullanma}

Açıklama

Örnek Atasözleri

$\mathrm{Bu}$ yöntem, ikna sürecinde hiçbir zor gücü kullanmadan Tatlı dil yılanı deliğinden veya maddi kazanç sunmadan, çeşitli yolarla rızasını almak veya ikna etmek suretiyle alıcının ilgili konudaki görüş, tutum veya davranışlarının istenilen yönde değiştirilmesini/ oluşturulmasını içerir.

$\mathrm{Bu}$ yöntem, ikna sürecinde çeşitli yollarla maddiyat/para sağlayarak/vererek alıcının ilgili konudaki görüş, tutum veya davranışlarının istenilen yönde değiștirilmesini/ oluşturulmasını içerir.

$\mathrm{Bu}$ yöntem, ikna sürecinde tehdit, korku ve şantaj gibi çeşitli şekillerde zor gücü kullanarak alıcının ilgili konudaki görüş, tutum veya davranışlarının istenilen yönde değiştirilmesini/ oluşturulmasını içerir.

2. Kategori: İKNA ETMEYİ KOLAYLAŞTIRAN FAKTÖRLER

Etkili ve güzel konușma; konuşmanın diksiyon, seçilen sözcükler, bilgi içeriği, jest ve mimik gibi yönlerden güçlü olmasını ifade eden bir olgudur ve bu olgu ikna sürecinde alıcının ikna olmasını kolaylaştıran faktörden biridir.

Alıcının; genel kültür, bilgi seviyesi, algılama ve anlama kapasitesi, kod açma, kod çözme ve geri bildirim yeteneği gibi donanımsal özelliklerinin güçlü ve yüksek olması, çoğunlukla ikna sürecini kolaylaştıran faktörlerden biridir.

Doğru zamanlama; bir işin, iletişsimin veya eylemin uygun ve doğru zamanda başlatılmasını ifade eden bir olgudur ve bu olgu ikna sürecinde alıcının ikna olmasını kolaylaştıran faktörden biridir.

Doğru yöntem ve araç kullanma; bir işin veya eylemin, o işe veya eyleme mümkün olan en uygun olan yöntem ve araçlarla yapılmasını ifade eden bir olgudur ve bu olgu ikna sürecinde alıcının ikna olmasını kolaylaştıran faktörden biridir. çıkarır.

$\mathrm{Al}$ ile aslan tutulur, güç ile gücigen (köstebek) tutulmaz. Zorla güzellik olmaz.

Altın anahtar her kapıyı açar. Paranın konuştuğu yerde her dil susar.

Para en iyi elçidir.

Kızını dövmeyen dizini döver.

Zorsuz bir șey olmaz. Zor oyunu bozar.

Örnek Atasözleri

İyi söz demir kapıyı açar. Söz var iş bitirir, söz var baş yitirir.

Dil kilıçtan keskindir

Arif olana bir söz yeter. Leb demeden leblebiyi anlar. Tereciye tere satılmaz.

Terazi var, tartu var, her şeyin bir vakti var. Demir tavında, dilber çağında.

Ağaç yaş iken eğilir.

Çay kuşu ayağından tutulur. Yemeğe tuz, söze şeker koymali.

Her tencereye bir kapak bulunur. 
2.5. Hatır ve İyi Nam

2.6. Doğruluk

\section{7. İstekli ve Israrlı Olmak}

2.8. Sabırlı Olmak

\subsection{Yalan Söylemek}

3.3. Yanlış Zamanlama

\subsection{Yanlış Yöntem ve Araç Kullanma}

\subsection{Kaynağın Fiziki Eksiklikleri}

\subsection{Mesajin Geğreğinden Fazla Tekrarlanması}

\subsection{Kötü Ün/Nam}

Hatır ve iyi nam; bir kişinin veya tarafin ya genelde sahip olduğu iyi nam ya da bire bir ilişkilerde karşı tarafta oluşturduğu hatır ile karşı tarafin gözünde değerinin ve etkisinin fazla olmasını ifade eden bir olgudur ve bu olgu ikna sürecinde alıcının ikna olmasını kolaylaştıran faktörden biridir.

Doğruluk; kişinin her zaman ve durumda doğru olanı söylemesi ve yapmasını ifade eden bir olgudur ve bu olgu ikna sürecinde alıcının karșı tarafa olan güvenini artırarak ikna olmasını kolaylaşturan faktörden biridir.

İstekli ve 1srarlı olmak; bir kișinin veya tarafın, bir konuda karşı taraftan isteği şeyle ilgili olarak isteğinden hiç vazgeçmeden devamlı istekli ve 1srarlı olmasını ifade eden bir olgudur ve bu olgu ikna sürecinde alıcının ikna olmasını kolaylaştıran faktörden biridir.

Sabırlı olmak; bir iş veya konuyla ilgili olarak, bir kişinin, grubun veya acentenin acele etmeden, sabır ve sükûnet göstererek, akli selim bir şekilde ilerlemesini ifade eden bir olgudur ve bu olgu ikna sürecinde alıcının ikna olmasını kolaylaşturan faktörden biridir.

3. Kategori: İKNA ETMEYİ ZORLAŞTIRAN FAKTÖRLER

Bir selâm bin hatır yapar.

Bir fincan kahvenin kirk y1

hatırı vardır.

Başım üstünde yeri var.

Haklı söz, haksızı Bağdat'tan çevirir.

Bir emin iki yeminden evla. Doğru söze akan sular durur.

\section{Ağlamayana meme}

vermezler.

Azimli fare duvarı deler.

Azimle sıçan mermeri deler.

Sabır ile bitmez iş olmaz.

Sabreden derviş muradına ermiș.

Cehd ve sabırla, sıçan tahtayı deler. Açıklama

Örnek Atasözleri

Alıcının algılama, kod çözme, konu hakkındaki bilgi seviyesi, genel kültürü, hayat görüşü, huyu ve kişiliği gibi donanımsal ve yapısal eksiklikleri, iletişimde sürecinde alıcının konuyu anlamasını ve karșı tarafla anlașmasını zorlaştıran bir olgudur ve bu olgu ikna sürecinde alıcının ikna olmasını zorlaștıran faktörden biridir.

Yalan söylemek; kișinin bazı zamanlarda ve durumlarda karşı tarafa doğru olanı değil de yalan söylemesini ifade eden bir olgudur ve bu olgu ikna sürecinde alıcının ikna olmasını zorlaştıran faktörden biridir.

Yanlış zamanlama; bir işin, o işe pek uygun olmayan zamanda, yani yanlıs zamanda yapılmasını ifade eden bir olgudur ve bu olgu ikna sürecinde alıcının ikna olmasını zorlaştıran faktörden biridir.

Yanlış yöntem ve araç kullanma; bir işin veya eylemin, o işe veya eyleme pek uygun olmayan, yanlış yöntem ve araçlarla yapılmasinı ifade eden bir olgudur ve bu olgu ikna sürecinde alıcının ikna olmasını zorlaştıran faktörden biridir.

Fiziki eksiklikler; kaynağın çirkin veya tipsiz olması, aşırı şişman veya zayıf olması, kötü giyinmiş veya bakımsız olması gibi bedenen somut ve görünür özelliklerinin kötü veya eksik olmasiyla ilgili bir olgudur ve ikna sürecinde alıcının ikna olmasını zorlaștıran faktörden biridir.

İletişim sürecinde kaynağın mesajı alıcıya gereğinden fazla ve sık bir şekilde göndermesi, genellikle alıcıyı sıkar ve bu durum ikna sürecinde alıcının ikna olmasını zorlaştıran faktörden biridir.

Kötü ün/nam; geçmişte yaşananlardan dolayı bir kişinin, grubun veya acentenin adının kötüye çıkmasını, kötü üne sahip olmasinı ifade eden bir olgudur ve bu olgu ikna sürecinde kaynağın alıcı üzerindeki inandırıcılığını ve etkisini düşürerek, ikna olmasını zorlaştran faktörden biridir.
Anlayana sivrisinek saz, Gafile kelâm, nafile kelâm. Çürük tahta çivi tutmaz.

Ardıcın közü olmaz, yalancının sözü olmaz. Yalancının şahitliği tutmaz.

Papaz her gün pilav yemez. Her vakit kedi kaymak yemez.

Arpa unundan kadaylf olmaz.

Sahin ile deve avlanmaz. Kuru torba ile at tutulmaz.

Börküm eski, sözüm geçmez.

Sakalım yok ki sözüm geçsin.

Cok söyleme arsiz olur. Çok söyleme arsız olur, az verme hirsiz olur.

Adı çıkmış dokuza inmez sekize.

Bir adamın adı çıkacağına canı çısın.

Dillere düştü. anlamayana davul zurna az. 


\begin{tabular}{|c|c|c|c|}
\hline \multicolumn{4}{|c|}{ 4. $\quad$ Kategori: İKNA EDECEK KİŞİDE OLMASI GEREKEN ÖZELLİKLER } \\
\hline & Alt Kategoriler & Açıklama & Örnek Atasözleri \\
\hline 4.1. & $\begin{array}{l}\text { Etkili ve Güzel } \\
\text { Konuşma Yeteneği }\end{array}$ & $\begin{array}{l}\text { Etkili ve güzel konuşma yeteneği; bir kişinin diksiyon, } \\
\text { seçtiği sözcükler, bilgi, jest ve mimik gibi yönlerden güçlü } \\
\text { bir konuşma yeteneğine sahip olmasını ifade eden bir } \\
\text { olgudur ve ikna edecek kişinin böyle bir yeteneğe sahip } \\
\text { olması ikna sürecinde alıcının ikna olmasını kolaylaştıran } \\
\text { faktörden biridir. }\end{array}$ & $\begin{array}{l}\text { Adamı ikrarından hayvanı } \\
\text { yularından tutarlar. } \\
\text { Anlatı̧̧a göre verirler fetvayı. } \\
\text { Söz ola kese savaşı, söz ola } \\
\text { kestire başı. }\end{array}$ \\
\hline 4.2. & $\begin{array}{l}\text { Yetenekli ve Zeki } \\
\text { Olma }\end{array}$ & $\begin{array}{l}\text { Yetenekli ve zeki olmak; bir kişinin, bir işi kavrama, } \\
\text { anlama, çözme ve yapabilme zekâsının ve kapasitesinin } \\
\text { yüksek olması, bir işle ilgili kendine yol çizebilmesi, işi } \\
\text { yaparken karşılaşabileceği zorlukların üstesinden gelmesiyle } \\
\text { ilgili bir olgudur ve bu olgu ikna sürecinde alıcının ikna } \\
\text { olmasını kolaylaştıran faktörden biridir. }\end{array}$ & $\begin{array}{l}\text { Herkes kaşık yapar ama } \\
\text { sapını ortaya getiremez. } \\
\text { Herkes sakız çiğner ama } \\
\text { çatlatamaz. } \\
\text { Leb demeden leblebiyi anlar. }\end{array}$ \\
\hline 4.3. & $\begin{array}{l}\text { Fiziksel } \\
\text { Özelliklerin İyi } \\
\text { Olması }\end{array}$ & $\begin{array}{l}\text { Bedenen güzel veya yakışıklı olmak, vücut ebatlarının } \\
\text { standartlarda, iyi olması, giyim-kuşamın uyumlu ve güzel } \\
\text { olması ve ses tonu ve bakışının iyi olması gibi kişinin } \\
\text { görünür ve somut fiziki özelliklerinin iyi olması, ikna } \\
\text { sürecinde alıcıyı olumlu yönde etkileyen bir olgudur ve } \\
\text { alıcının ikna olmasını kolavlastıran faktörden biridir. }\end{array}$ & $\begin{array}{l}\text { Cesurun bakışı, korkağın } \\
\text { k1lıcından keskindir. } \\
\text { Kaş ile göz gerisi söz. }\end{array}$ \\
\hline
\end{tabular}

Tablo 2'ye bakıldığında bu araştırmada kullanılan temel kategoriler ve alt kategorilerin verildiği, bu kategorilerin ikna ile ilişkilerinin kısaca açıklandığı ve bu kategorilerle ilgili örnek atasözlerinin verildiği görülmektedir.

\section{Bulgular}

\subsection{Tutum ve Davranışları Değiştirme/Oluşturma Yöntemleriyle İlgili Atasözleri}

İnsanların tutum ve davranışlarını değiştirme/oluşturma yöntemleriyle ilgili Türk atasözleri taranmış, derlenen veriler incelenmiş ve elde edilen bulgular Tablo 3’te verilmiştir.

Tablo 3. Tutum ve Davranıslar Değgstirme/Olusturma Yöntemleriyle İlgili Atasözleri

\begin{tabular}{lcc}
\hline Tutum ve Davranışlanı Değiştirme/Oluşturma Yöntemleri & Sayı & Frekans (\%) \\
\hline İkna Etme/Rıza Alma & 37 & 59,7 \\
Maddi Çıkar/Para Sağlamak & 15 & 24,2 \\
Zor Kullanma & 10 & 16,1 \\
\hline Toplam & $\mathbf{6 2}$ & $\mathbf{1 0 0}$
\end{tabular}

Tablo 3 incelendiğinde tutum ve davranışları değiştirme/oluşturma yöntemleriyle ilgili olarak toplam 62 adet atasözü bulunduğu görülmektedir. Literatür kapsamında bu atasözleri "İkna Etme/Rıza Alma, Maddi Çıkar/Para Sağlamak ve Zor Kullanma”, şeklinde üç yöntemde incelenmiştir. Bu yöntemlerin altına yığılan atasözleri incelendiğinde, Türk atasözlerinde en fazla "İkna Etmeye/Rıza Alma" (\%59,7) yöntemine ve en az ise "Zor Kullanma" (\%16,1) yöntemine vurgu yapıldığı görülmektedir.

\section{2. İkna Etmeyi Kolaylaştıran Faktörlerle İlgili Atasözleri}

İkna kavramıyla ilgili Türk atasözleri taranmış, derlenen veriler incelenmiş ve ikna etmeyi kolaylaştıran faktörlerle ilgili elde edilen bulgular Tablo 4'te verilmiştir.

Tablo 4. Ikna Etmeyi Kolaylastıran Faktörlerle Iloili Atasözleri

\begin{tabular}{lcc}
\hline İkna Etmeyi Kolaylaştıran Faktörler & Sayı & Frekans (\%) \\
\hline Etkili ve Güzel Konuşma & 27 & 33,7 \\
Alıcının Donanımlı Olması & 6 & 7,5 \\
Doğru Zamanlama & 10 & 12,5 \\
Doğru Yöntem ve Araç Kullanma & 17 & 21,2 \\
Hatır ve İyi Nam & 7 & 8,7 \\
Doğruluk & 5 & 6,3 \\
İstekli ve Israrlı Olmak & 5 & 6,3 \\
Sabırlı Olmak & 3 & 3,8 \\
\hline Toplam & $\mathbf{8 0}$ & $\mathbf{1 0 0}$ \\
\hline
\end{tabular}


Tablo 4'e bakıldığında ikna etmeyi kolaylaştıran faktörlerle ilgili olarak toplam 80 adet atasözü bulunduğu görülmektedir. Bu atasözleri anlam boyutuna göre kategorilere ayrıldığında Türk atasözlerinde ikna etmeyi kolaylaştıran faktörler olarak "Etkili ve Güzel Konuşma, Alıcının Donanımlı Olması, Doğru Zamanlama, Doğru Yöntem ve Araç Kullanma, Hatır ve iyi Nam, Doğruluk, İstekli ve Israrlı Olmak ve Sabırlı Olmak" şeklinde toplam 8 faktörün ortaya çıktı̆ı görülmüştür. Bu faktörlerin altına yığılan atasözleri incelendiğinde, Türk atasözlerinde ikna etmeyi kolaylaştıran faktörlerden en fazla "Etkili ve Güzel Konuşma" (\%34,6) faktörüne ve en az ise "Sabırlı Olmak" (\%3,9) faktörüne yer verildiği görülmektedir.

\section{3. İkna Etmeyi Zorlaştıran Faktörlerle İlgili Türk Atasözleri}

İkna, kavramıyla ilgili Türk atasözleri taranmış, derlenen veriler incelenmiş ve ikna etmeyi zorlaştıran faktörlerle ilgili elde edilen bulgular Tablo 5’te verilmiştir.

Tablo 5. İkna Etmeyi Zorlaștran Faktörlerle Illgili Atasözleri

\begin{tabular}{lcc}
\hline İkna Etmeyi Zorlaştıran Faktörler & Say1 & Frekans (\%) \\
\hline Alıcının Yapısal ve Donanımsal Eksiklikleri & 45 & 54,9 \\
Yalan Söylemek & 5 & 6,1 \\
Yanlış Zamanlama & 7 & 8,5 \\
Yanlış Yöntem ve Araç Kullanma & 11 & 13,4 \\
Kaynağın Fiziki Eksiklikleri & 4 & 4,9 \\
Mesajın Geğreğinden Fazla Tekrarlanması & 4 & 4,9 \\
Kötü Ün/Nam & 6 & 7,3 \\
\hline Toplam & $\mathbf{8 2}$ & $\mathbf{1 0 0}$ \\
\hline
\end{tabular}

Tablo 5 gözlendiğinde ikna etmeyi zorlaştıran faktörlerle ilgili toplam 82 adet atasözü bulunduğu görülmektedir. Bu atasözleri anlam boyutuna göre kategorilere ayrrldığında Türk atasözlerinde ikna etmeyi zorlaştıran faktörler olarak "Alıcının Yapısal ve Donanımsal Eksiklikleri, Yalan Söylemek, Yanlış Zamanlama, Yanlış Yöntem ve Araç Kullanma, Kaynağın Fiziki Eksiklikleri, Mesajın Geğreğinden Fazla Tekrarlanması ve Kötü Ün/Nam” şeklinde toplam 7 faktörün ortaya çıktığı görülmüştür. Bu faktörlerin altına yığılan atasözleri incelendiğinde, Türk atasözlerinde ikna etmeyi zorlaşturan faktörlerden en fazla "Alıcının Yapısal ve Donanımsal Eksiklikleri”" (\%54,9) faktörünün ve en az ise "Kaynağın Fiziki Eksiklikleri”" (\%4,9) ve "Mesajın Gereğinden Fazla Tekrarlanması" (\%4,9) faktörlerinin vurgulandığ1 görülmektedir.

\section{4. İkna Edecek Kişide Olması Gereken Özelliklerle İlgili Türk Atasözleri}

İkna, kavramılla ilgili Türk atasözleri taranmış, derlenen veriler incelenmiş ve ikna edecek kişide olması gereken özelliklerle ilgili elde edilen bulgular Tablo 6'da verilmiştir.

Tablo 6. İkna Edecek Kişide Olması Gereken Özelliklerle İlgili Atasözleri

\begin{tabular}{lcc}
\hline İkna Edecek Kişide Olması Gereken Özellikler & Say1 & Frekans (\%) \\
\hline Etkili ve Güzel Konuşma Yeteneği & 27 & 84,4 \\
Yetenekli ve Zeki Olma & 3 & 9,4 \\
Fiziksel Özelliklerin İyi Olması & 2 & 6,3 \\
\hline Toplam & $\mathbf{3 2}$ & $\mathbf{1 0 0}$ \\
\hline
\end{tabular}

Tablo 6 incelendiğinde ikna edecek kişide olması gereken özelliklerle ilgili toplam 32 adet atasözü bulunduğu görülmektedir. Bu atasözleri anlam boyutuna göre kategorilere ayrıldığında Türk atasözlerinde ikna edecek kişide olması gereken özellikler olarak "Etkili ve Güzel Konuşma Yeteneği, Yetenekli ve Zeki Olma ve Fiziksel Özelliklerin İyi Olması" şeklinde toplam 3 faktörün ortaya çıktığı görülmüştür. Bu faktörlerin altına yığılan atasözleri incelendiğinde, Türk atasözlerinde ikna edecek kişide olması gereken özelliklerden en fazla "Etkili ve Güzel Konuşma Yeteneği” (\%84,4) faktörüne ve en az ise "Fiziki Özelliklerin İyi Olması” (\%6,3) faktörüne yer verildiği görülmektedir. 


\section{Sonuç ve Tartışma}

Bilim ve teknolojide yașanan baș döndürücü gelișmeler günümüzde insanlara hemen her ihtiyacını karşılama noktasında oldukça fazla alternatif sunmaktadır. Buna paralel olarak insan haklarının, demokrasinin ve özgürlüklerin de son derece gelişmesi, bireylerin hemen her konuda kendi kararlarını kendilerinin vermesine yol açmıştır. Bu durum çağdaş dünyada faaliyet gösteren hemen hemen her iş dalında üreticiyi hedef kitleyi ikna etme olgusuyla ve bireyleri de ihtiyaçlarını karşılama ve kararlarını verme noktasında ikna edilme olgusuyla baş başa bırakmıştır. Öyle ki siyasetten spora, üretimden tüketime ve eğitimden eğlenceye hayatın hemen her alanında insanlar ikna etme ya da edilme durumuyla yoğun olarak karşı karşıya kalmaktadır. Bu yüzden günümüzde bir toplumun ve o toplumu oluşturan bireylerin ikna olgusuna yaklaşımının öğrenilmesi, o toplum veya toplumun bir kesimini oluşturan bireyleriyle ilgili yapılması düşünülen bir işte başarı sağlanması açısından elzemdir. Bu bağlamda bu çalışmada Türk toplumunun ikna olgusuna verdiği önem, ikna ile ilgili üzerinde durduğu konular ve vurguladığı yönlerin ortaya konulması amaçlanmıştır. Bu amacın gerçekleştirilmesi için çalışmada dört araştırma sorusuna cevap aranmıştır. Yapılan araştırmalar ve elde edilen bulgular incelendiğinde bu araştırma sorularılla ilgili çıkan sonuçlar ve sonuçların tartışması şu şekildedir:

Birinci araştırma sorusu; Türk atasözlerinde tutum değiștirme/oluşturma yöntemlerinden "İkna Etme"ye ne kadar vurgu yapılmıştır? Birinci temel kategoriyi oluşturan bu araştırma sorusuyla ilgili olarak literatür bağlamında ele alınan üç temel tutum değiştirme/oluşturma yöntemiyle ilgili olarak toplam 62 adet Türk atasözü bulunmuştur. Bu atasözleri incelendiğinde; Türk atasözlerinde tutum değiştirme/oluşturma yöntemlerinden en çok "İkna Etme/Rıza Alma" yöntemine (37), ikinci olarak "Maddi Çıkar/Para Sağlama" yöntemine (15) ve en az ise "Zor Kullanma" yöntemine (10) vurgu yapıldığ görülmüştür. Bu sonuç, Türk toplumunun insan işleri ve ilişkilerinde "İkna Etme/Rıza Alma" yöntemini fazlaca benimsediğini $(\% 59,7)$ ve "Zor Kullanma" yöntemini ise pek benimsemediğini (\%16,1), hatta "Maddi Çıkar/Para Sağlama" yöntemini $(\% 24,2)$ bile "Zor Kullanma" yöntemine $(\% 16,1)$ göre daha fazla benimsediğini göstermektedir. Araştırmada ortaya çıkan bu sonuçtan hareketle, Türk toplumunun iknaya/rnzaya çok fazla önem veren demokratik bir toplum olduğu, buna karşın zor gücüne karşı olduğu ve bu bağlamda insan işleri ve ilişkilerini daha çok hoşgörüyle ele aldığı söylenebilir.

İkinci araştırma sorusu; Türk atasözlerinde ikna etmeyi kolaylaştırmaya yönelik vurgu yapilan faktörler nelerdir? İkinci temel kategoriyi oluşturan bu araştırma sorusuyla ilgili olarak toplam 80 adet Türk atasözü bulunmuştur. Bu atasözleri incelendiğinde; Türk atasözlerinde ikna etmeyi kolaylaştıran faktörlerden en fazla "Etkili ve Güzel Konuşma" faktörüne (27) vurgu yapıldığ1 görülmüştür. İkinci olarak "Doğru Yöntem ve Araç Kullanma" faktörüne (17) ve üçüncü olarak "Doğru Zamanlama" faktörüne (10) vurgu yapıldığı görülürken, en az "Sabırlı Olmak" (3) faktörü olmak üzere diğer faktörlere de (5, 5, 6, 7) az vurgu yapıldığı görülmüştür. Bu sonuçtan, Türk toplumunun iknada sabır olgusuna pek önem vermediği $(\% 3,8)$ ve bu bağlamda pek sabırlı bir toplum olmadığ söylenebilir. Yine benzer şekilde Türk toplumunun iknayı kolaylaştırması noktasında doğruluğa $(\% 6,3)$, istekli ve 1 strarlı olmaya $(\% 6,3)$, hatır ve iyi nama $(\% 8,7)$ ve alıcının donanımına $(\% 7,3)$ da pek önem vermediği görülmektedir. Değerlere önem veren, hatta 2017 yllında Millî Eğitim Bakanlığı tarafindan eğitim müfredatına konulan 10 kök değer "adalet, dostluk, dürüstlük, öz denetim, sabır, sayg1, sevgi, sorumluluk, vatanseverlik, yardımseverlik" ile bu değerleri benimsemiş bireyler yetiştirmeyi hedefleyen Türk toplumu için bu faktörlerle ilgili çıkan bu sonuçların aslında bir tezat oluşturduğu söylenebilir. Bu faktörlere karşın Türk toplumunun iknayı kolaylaştırması noktasında "Doğru Zamanlama" (\%12,5) ile "Doğru Yöntem ve Araç Kullanma" (\%21,2) faktörlerine orta düzeyde önem verdikleri görülmektedir. Bu iki faktörle ilgili çıkan sonuçlarla ilgili olarak MEB'in müfredata koyduğu 10 kök değerden biri olan dürüstlük/doğruluk değerine, ikna olgusunda zaman, yöntem ve araç bağlamında vurgu yapıldığı söylenebilir.

İkinci araştırma sorusuyla ilgili çıkan en önemli sonuç, Türk toplumunun ikna etmeyi en fazla kolaylaştıran faktör olarak "Etkili ve Güzel Konuşma" (33,7) faktörünü görmesi, başka bir deyişle kaynağın konuşmasının etkinliğini ikna etmeyi kolaylaştıran en önemli faktör olarak görmesidir. Öncelikle bu sonucun dördüncü araştırma sorusunda yer alan "Etkili ve Güzel Konuşma Yeteneği”" faktörüyle ilgili çıkan sonuçla benzer bir sonuç olduğunu belirtmek gerekir. Zira dördüncü araştırma sorusu şu şekildedir: Türk atasözlerinde ikna edecek kişide olması gereken özelliklere yönelik vurgu yapılan faktörler nelerdir? 
Dördüncü temel kategoriyi oluşturan bu araştırma sorusuyla ilgili olarak toplam 32 adet Türk atasözü bulunmuştur. $\mathrm{Bu}$ atasözleri incelendiğinde; Türk atasözlerinde ikna edecek kişide olması gereken özelliklerden en fazla "Etkili ve Güzel Konuşma Yeteneği" faktörüne (27) vurgu yapıldığı görülmektedir. İkinci olarak "Yetenekli ve Zeki Olma" faktörüne (3) vurgu yapıldığ1 görülürken, en az ise "Fiziki Özelliklerin İyi Olması" faktörüne (2) vurgu yapıldığı görülmektedir. Burada etkili ve güzel konuşma yeteneğine \%84,4 oranında ezici bir ağırlıkla yapılan vurgu, bize Türk toplumunun ikna edecek kişide aradığ1 en önemli, neredeyse tek faktörün "Etkili ve Güzel Konuşma" faktörü olduğunu göstermektedir. Çünkü diğer iki faktöre yapılan \%9,4 ile \%6,3'lük vurguların, toplam üç faktörün olduğu bir grupta çok küçük ve önemsiz olduklanı açıktır. Dolayısıyla hem ikinci araştırma sorusuyla ilgili hem de dördüncü araştırma sorusuyla ilgili ortak çıkan bir sonuç olarak, Türk toplumunun "ikna etme/rrza alma" olgusunda "Etkili ve Güzel Konuşma" faktörüne son derece önem verdiği görülmektedir. Bu sonuç, Türk toplumunun kökeni çok eskilere dayanan güçlü bir sözlü kültürünün olmasıyla açıklanabilir. Çünkü konuşma, sözlü kültürün en temel ögesidir. Muharrem Ergin, O. Nedim Tuna, Kemal Balkan ve Landsberger gibi bilim adamlarının çalş̧maları bize Türkçe'nin en az 5000 yılllk bir sözel döneminin olduğunu göstermektedir (Balkan, 1992). Bu açıdan Türk toplumunun ve dilinin çok eski ve güçlü bir sözlü kültürü olduğu açıktır. Sözlü kültürü oluşturan unsurlar yazılı kültürün unsurlarına göre bir toplumu oluşturan bireyler üzerinde daha etkilidir ve toplum hayatında daha büyük ve geniş bir kabule sahiptir. Başka bir ifadeyle bir toplumun milli kimliğini oluşturan ortak değerler ve kabuller büyük ölçüde o toplumun sözlü kültürü içinde oluşmaktadır (Yıldırım, 1989, s. 16). Sonuç itibariyle bilim adamlarının özelde Türk dili ve kültürü, genelde ise sözlü kültür ile ilgili olarak ortaya koyduklan bu savlar, bu çalışmada ortaya çıkan bu sonucu destekler niteliktedir.

Üçüncü araştırma sorusu; Türk atasözlerinde ikna etmeyi zorlaştırmaya yönelik vurgu yapilan faktörler nelerdir? Üçüncü temel kategoriyi oluşturan bu araştırma sorusuyla ilgili olarak toplam 82 adet Türk atasözü bulunmuştur. Bu atasözleri incelendiğinde; Türk atasözlerinde ikna etmeyi zorlaştıran faktörlerden en fazla "Alıcının Yapısal ve Donanımsal Eksiklikleri” faktörüne (45) ve ikinci olarak "Yanlış Yöntem ve Araç Kullanma" faktörüne (11) vurgu yapıldığı görülürken, diğer faktörlere (4, 4, 5, 6, 7) az vurgu yapıldığ1 görülmüştür. Burada dikkat çeken en önemli sonuç, Türk toplumunun ikna etmeyi zorlaştıran faktörlerden "Alıcının Yapısal ve Donanımsal Eksiklikleri” faktörüne \%54,9 ile oldukça yüksek oranda vurgu yapmasina karşılık diğer faktörlere oldukça düşük oranlarda (\%13,4, \%8,5, \%7,3, \%6, 1, \%4,9 ve \%4,9) vurgu yapmasıdır. Bu çalışmada ikinci araştırma sorusuyla ilgili olarak Türk kültüründe ikna etmeyi kolaylaştıran en önemli faktör ve dördüncü araştırma sorusuyla ilgili olarak Türk kültüründe ikna edecek kişide olması gereken en önemli özellik olarak "Etkili ve Güzel Konuşma" faktörüne yüksek oranlarda vurgu yapıldığı sonuçlarına göre bu sonucun bir tezat oluşturduğu söylenebilir. Çünkü ikinci ve dördüncü kısımlarda "Etkili ve Güzel Konuşma" faktörüyle, Türk kültüründe ikna ile ilgili olarak kaynağa vurgu yapıldığı görülmesine karşın, iknayı zorlaştıran faktörlerde ise "Alıcının Yapısal ve Donanımsal Eksiklikleri” faktörüyle alıııya vurgu yapıldığı görülmektedir. Burada en önemli ikna engeli olarak alıcının eksikliklerinin görüldüğü bu sonuç, yapılan araştırmalarla da görüldüğü gibi başta Türk toplumunun okuma alışkanlığının düşük olması (Odabaş vd., 2008; Ortaş, 2014) gibi değişik nedenlerden dolay1 Türk toplumunda bireylerin kendilerini donanımlı olarak yetiştirememeleri ile ilgili olduğu söylenebilir. Bundan dolayı Türk toplumunda ikna ile ilgili gerçekleştirilen iletişim süreçlerinde alıcının donanımsızlığının en önemli ikna engeli olarak ortaya çıtığı söylenebilir.

\section{6. Öneriler}

Gelecekte Türk toplumu veya bireylerine yönelik tutum değiştirme/oluşturma çalışması yapacak olan politikacılara, araştırmacılara ve kısaca konuyla ilgilenen her kişi veya kuruma bu araştırmada;

Birinci araştırma sorusuyla ilgili elde edilen bulgulardan hareketle, mümkün mertebe ikna etme veya rıza alma yöntemine başvurmaları ve zor kullanma yönteminden uzak durmaları,

İkinci ve dördüncü araştırma sorularılyla ilgili elde edilen bulgulardan hareketle, ikna işinde kullanacakları kaynağın etkili ve güzel konuşma yeteneğine sahip olmasına ve

Üçüncü araştırma sorusuyla ilgili elde edilen bulgulardan hareketle, öncelikle ikna edilmek istenen tarafın, yani alııının yapısını ve özelliklerini çok iyi bir şekilde analiz etmeleri ve daha sonra bu analizler 
doğrultusunda alıcının yapısına uygun dil, kodlama, mesaj, kanal, yöntem ve zaman gibi ikna stratejileri belirlemeleri önerilir.

\section{Extended Abstract}

People face many alternatives and have to choose to do almost every job and meet their needs because of the significant developments in democracy, human rights, freedoms, production, and information communication technologies in our age. Therefore, the place of persuasion in human life, its importance, and usage areas are increasing day by day. The purpose of this study is to reveal the importance given to the method of "persuasion/consent" in Turkish culture and the factors emphasized about the phenomenon of "persuasion".

The main research question of the study is as follows: what is the emphasis on the "persuasion/consent" method in Turkish culture and the factors emphasized in persuasion in the proverbs? Sub-research questions to be answered in order to understand the question are as follows:

1. How much emphasis is given to "Persuasion," one of the methods of changing/creating attitudes in Turkish proverbs?

2. What are the factors emphasized in Turkish proverbs to facilitate persuasion?

3. What are the factors emphasized in Turkish proverbs to make it difficult to persuade?

4. What are the factors emphasized in Turkish proverbs regarding the characteristics that should be in the person to persuade?

The qualitative content analysis method was used in this study. Turkish proverbs were scanned using the method of "document analysis," and the proverbs related to the concept of "persuasion" were compiled in the study. The data were analyzed using the "categorical analysis" technique. The categories were created by the researcher, considering the meaning dimension.

The findings are as follows:

Sixty-two proverbs were found regarding changing/creating attitudes and behaviors. When these proverbs were examined in detail, it was found that the most emphasis was given to the "Persuasion" method and the least on the "Use of Force" method in Turkish culture.

Eighty proverbs were found on factors that facilitate persuasion. When these proverbs were examined, it was seen that the most emphasis was on the "Effective and Good Speaking" factor, while the least was the "Being Patient" factor among the factors that facilitate persuasion in Turkish culture.

Eighty-two proverbs were found about factors that make it challenging to persuade. When these proverbs were examined, it was seen that among the factors that make persuasion difficult in Turkish culture, the "Receiver's structural and knowledge deficiencies" factor was emphasized the most, and the least was the "Physical Deficiencies of the Source" and the "Excessive Repetition of the Message" factors.

Thirty-two proverbs were found about the characteristics that the person to persuade should have. When these proverbs were examined, it was found that among the characteristics that must be in the persuasive person in Turkish culture, the most emphasis was on the "Effective and Good Speaking Ability," and the least was the "Good Physical Properties" feature.

When these findings were investigated, the following results were obtained:

While Turkish society adopted the method of persuasion/consent from the methods of changing/creating attitude, and it was seen that they do not adopt the method of using force. Based on this result, it can be said that Turkish society is against despotism, democratic, and giving importance to consent. In this context, it is understood that to be successful in changing/creating attitudes towards Turkish society, and special attention should be given to use the persuasion/consent method, especially the use of force should be avoided.

It was found that Turkish society emphasized and attached importance to effective and eloquent speech among the factors that facilitate persuasion. In this context, it is understood that persuasion speaking is very important in Turkish society. Depending on this result, it can be said that Turkish society attaches the most importance to the beauty and effectiveness of the speech in persuasion since it has an oral culture that is extremely effective in the formation of its culture. It was also observed that the high rate of the ability to speak effectively and beautifully (84.4\%) was emphasized and given importance 
concerning the characteristics of the person who convinces. This result can also be considered in this context. In other words, it is possible to deduce that the phenomenon of speaking is highly valued in Turkish society since it has a strong oral culture and a long history.

It was observed that the Turkish society emphasized the receiver's structural and knowledge deficiencies the most, among the factors that made it difficult to persuade. It can be said that this result is a result of individuals' inability to raise themselves well-equipped in Turkish society due to various reasons. Therefore, the receiver's structural and knowledge deficiencies in the communication processes about persuasion in Turkish society may be accepted as the most important persuasion barrier.

\section{Kaynakça}

Aksan, D. (2007). Her yönüyle dil: Ana çizgileriyle dilbilim. Ankara: Türk Dil Kurumu Yayınları.

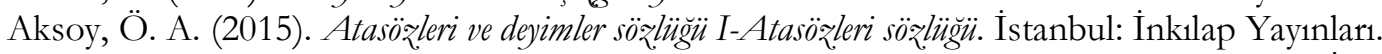

Aktan, C. C. \& Tutar, H. (2007). Bir sosyal sabit sermaye olarak kültür. Pazarlama ve İletişim Kültürü Dergisi, 6(20), 1-11.

Akyol, Z. (2019). Bir ikna teknolojisi olarak internet: E-ticaret sitelerindeki ikna dinamikleri üzerine bir inceleme. (Yayımlanmamış doktora tezi). Ege Üniversitesi Sosyal Bilimler Enstitüsü Reklamcıllk Anabilim Dalı, İzmir.

Altnörs, A. (2011). Platon ile Aristoteles'in retorik anlayışlarının karşılaşturılması. EKEV Akademi Dergisi, 15(49), 81-92.

Anık, C. (1997). Siyasal motivasyon ve ikna. (Yayımlanmamış doktora tezi). Gazi Üniversitesi Sosyal Bilimler Enstitüsü Halkla İlişkiler ve Tanıtım Anabilim Dalı, Ankara.

Anık, C. (2000). Siyasal ikna. Ankara: Vadi Yayınlanı.

Aristoteles, (2015). Retorik. (Çev. Doğan, M.). İstanbul: Yapı Kredi Yayınları.

Asna, M. A. (1968). Yönetim-halk ilişkileri. Amme İdaresi Dergisi, 1(3-4), 55-68.

Bahçecioğlu, E. H. (2021). Retoriğin temel unsurlanı olan ethos-pathos-logos perspektifinden ikna sanatının kullanılış: Müge Anlı örneği. Aksaray İletişim Dergisi, 3(1), 16-42.

Balc1, Ş. (2006). Negatif siyasal reklamlarda ikna edici mesaj stratejisi olarak korku cekiciliği kullanmm. (Yayımlanmamış doktora tezi). Selçuk Üniversitesi Sosyal Bilimler Enstitüsü Halkla İlişkiler ve Tanıtım Anabilim Dalı, Konya.

Balkan, K. (1992). Eski Önasya'da Kut (veya Gut) halkının dili ile eski Türkçe arasındaki benzerlik. Erdem, 6(16), 1-64.

Başarır, M. (2017). Seçmenlerin oy verme davranışları ile liderlerin hitaplarında aradıkları ikna bileşenleri ve üslup çeşitleri arasındaki ilişki. Inif E-Dergi, 1(2), 218-233.

Bettinghaus, E. P. \& Cody, M. J. (1987). Persuasive communications. New York: Holt, Rinehart and Winston Inc.

Bilgin, N. (1999). Sosyal psikolojide yöntem ve pratik çalışmalar. İzmir: Ege Üniversitesi Edebiyat Fakültesi Yayınları.

Bilgin, N. (2003). Sosyal psikoloji söəlü̆ü: Kavramlar, yaklaşımlar. İstanbul: Bağlam Yayınc1lık.

Brembeck, W. L. \& Howell, W. S. (1952). Persuasion, a means of social influence. New York: Prentice Hall.

Brembeck, W. L. \& Howell, W. S. (1976). Persuasion, a means of social influence (2. Baski) New York: Prentice Hall.

Ceylan, F. (2020). Siyasal rı̨a bağlammda oy verme davranıslarn üzerine bir araștıma: Emịncan ili örneği. (Yayımlanmamış doktora tezi). Erciyes Üniversitesi Sosyal Bilimler Enstitüsü İletişim Bilimleri Anabilim Dali, Kayseri.

Christophe, M. \& Renvoise, P. (2019). Beyindeki ikna kodu: Nöropazarlama ile bilimsel ikna stratejileri geliștirmek. İstanbul: Maltepe Üniversitesi Kitapları.

Çobanoğlu, Ö. (2004). Türk dünyası ortak atasöఇleri sǫ̈lüğ̈. Ankara: Atatürk Kültür Merkezi Başkanliğ1 Yayınlar1.

Demirtaş, H. A. (2004). Temel ikna teknikleri: Tutum oluşturma ve tutum değiştirme süreçlerindeki etkilerinin altunda yatan nedenler üzerine bir derleme. Gaæi Üniversitesi İletisim Fakültesi Dergisi, 19, 73-91.

Dilçin, D. (2000). Edebiyatımı̨̧da atasöそৃleri (2. Baskı). Ankara: Türk Dil Kurumu Yayınları.

Elden, M. \& Bakır, U. (2010). Reklam çekicilikleri-cinsellik, miz̧ah, korku. İstanbul: İletişim Yayınlanı. 
Geray, H. (2017). İletisism alanndan örneklerle toplumsal araștımalarda nicel ve nitel yöntemlere giriș. Ankara: Ütopya Yayınlanı.

Gökalp, Z. (1997). Türkçülïğ̈̈n esasları. İstanbul: İnkılap Kitabevi.

Güz, H. (1998). Reklamlarda ikna stratejileri. (Yayımlanmamış doktora tezi). Gazi Üniversitesi Sosyal

Bilimler Enstitüsü Halkla İlişkiler ve Tanıtım Anabilim Dalı, Ankara.

Herkner, W. (2003). İçerik çözümlemesi. Murat S. Çebi (Der. ve Çev.), İletişim Araştrmalarnnda İ̧erik

Cö̈zümlemesi, içinde (ss. 124-176). Ankara: Alternatif Yayınları.

Hofstede, G. (1980). Culture's consequences and international differences in work related values. London: Sage

Publications.

Huseynli, B., Engizek, N. \& Kurtuluş, S. (2018). Tüketicilerin fiyat taktiklerinin ikna kabiliyeti ile ilgili

bilinç düzeyi ölçeğinin Türkçeye uyarlanması. Yıldız Social Science Review, 4(1), 65-78.

İplikçi, H. G. (2015). Reklamlarda tüketiciyi ikna etmek için kullanılan stratejiler ve reklam

örnekleri. Sosyal ve Beşeri Bilimler Dergisi, 7(1), 65-77.

Jamieson, H. (1996). İletişim ve ikna. (Çev. Atabek, N. ve Dağtaş, B.), Eskişehir: Anadolu Üniversitesi

Eğitim Sağlık ve Bilimsel Araşıtıma Çalışmaları Yayınları.

Köknel, Ö. (1981). Cumburiyet gençliği ve sorunlarr. İstanbul: Cem Yayınevi.

Kurudayığlu, M. \& Yilmaz, E. (2014). How are we persuaded? Persuasive text and structure/Nasil

ikna ediliyoruz? İkna edici metin ve yap1sı. Eğitimde Kuram ve Uygulama, 10(1), 75-102.

Küçükkurt, M. (1987). Zihin davranış ilişkilerinde mesaj stratejisi. Düşünceler, 1(1), 43-50.

Lewis, B. (2011). Modern Türkiye'nin doğışu (5. Baskı). (Çev. Turna, B. B.). Ankara: Arkadaş Yayınevi.

Milli Kütüphane Başkanllğı. (1971). Türk atasözsözleri I (Haz: Milli Kütüphane Genel Müdürlüğü).

İstanbul: Milli Eğitim Basımevi.

Montesquieu, C. (2004). Kanunlarn rubu üzerine. (Çev. Baldaş, F.). İstanbul: Seç Yayın Dağtım.

Odabaş, H., Odabaş, Y. \& Polat, C. (2008). Üniversite öğrencilerinin okuma alışkanlığı: Ankara

Üniversitesi örneği. Bilgi Dünyası, 9(2), 431-465.

O'Keefe, D. J. (1990). Persuasion: Theory of research. Newbury Park, CA: Sage Publications.

Okur, A., Süğümlü, Ü. \& Göçen, G. (2013). İkna edici konuşma ve karşılaştırmalı bir araştırma (Avustralya ana dili öğretimi ders materyalleri ve Türkçe örneği). Turkish Studies, 8(8), 951-970.

Ortaş, İ. (2014). Türkiye ve dünyada kitap okuma değerlerinin karşılaştırması ve sosyal yaşamımıza etkileri. Türk Kütüphaneciliği, 28(3), 323-337.

Pala, İ. (1999). Ata sö:leri. İstanbul: Deniz Yayınları.

Perloff, R. M. (2010). The dynamics of persuasion: Communication and attitudes in the 21st century (4th Edition).

New York: Routledge Taylor \& Francis

Raven, B. H. \& Haley, R. W. (1982). Social influence and compliance of hospital nurses with infection control policies. R. J. Eiser (Ed.), Social Psychology and Behavioral Medicine içinde (ss. 413-438). New York: John Wiley \& Sons.

Reardon, K. K. (1991). Persuasion in practice. London: Sage Publications.

Rousseau, J. J. (2012). Toplum sözleşmesi. (9. Basım). (Çev. Günyol, V.) İstanbul: Türkiye İş Bankası Kültür Yayınları.

Tarakçı, H. N. (2019). İkna edici mesaj stratejisi olarak cekicilik ve kamu spotlarnnda kullammı. (Yayımlanmamış doktora tezi). Selçuk Üniversitesi Sosyal Bilimler Enstitüsü Halkla İlişkiler ve Tanıtım Anabilim Dalı, Konya.

Timisi, N. \& Dursun, Ç. (2003). Medya ve deprem: 17 Ağustos 1999 depreminin medyada temsili. Ankara: RTÜK Eğitim Dairesi Başkanlı̆̆ Yayını.

Topçu, N. (2011). Yarnnki Türkiye. İstanbul: Dergâh Yayınları.

Tortop, N. (1986). Halkla iliskiler. Ankara: İlk-San Matbaası.

Tuna, D. (2016). Bir yazınsal yapıt ve çevirileri üzerinden propaganda, ikna ve nza söylemlerini okumak. RumeliDE Dil ve Edebiyat Arasturmalar Dergisi, 7, 87-106.

Tutar, H. (2014). Sosyal psikoloji: Kavramlar ve kuramlar. (2. Baski). Ankara: Seçkin Yayıncılık.

Tylor, E. B. (1985). Primitive culture and leadership. San Fransisco: Jossey-Bass.

Usal, A. \& Kuşluvan, Z. (1999). Davranıs bilimleri. İzmir: Barış Yayınları. 
Üstündağ, L. \& Akengin, G. (2020). TV reklamlarında kullanılan grafik tasarımların mesaj ve ikna kavramı üzerine etkisi. Süleyman Demirel Üniversitesi Sosyal Bilimler Enstitüsï Dergisi, 37, 38-65.

Yaşar Uğurlu, Ö. \& Harbi, K. (2018). Girişimcilik olgusunun Türk atasözlerinde içerik analizi yöntemiyle incelenmesi. Mustafa Kemal Üniversitesi Sosyal Bilimler Enstitïsü Dergisi, 15(41), 128-146.

Yaşar, F. Ö. (2007). Bilgi toplumu bağlamında Türk atasözlerinde "eğitim" ve "bilgi" kavramları üzerine düşünceler. Elektronik Sosyal Bilimler Dergisi, 6(19), 146-158.

Yıldırım, D. (1989). Sözlü kültür ve folklor kavramları üzerine düşünceler. Millh Folklor, 1(3), 16-17.

Yiğitbaşı, K. G. (2012). İkna edici iletişim sürecinde siyasal mesaj tasarmı. (Yayımlanmamış doktora tezi). Marmara Üniversitesi Sosyal Bilimler Enstitüsü Gazetecilik Anabilim Dalı, İstanbul.

Yüksel, A. H. (2005). İkna ve konuşma. Eskişehir: Anadolu Üniversitesi Yayınları. 